\title{
Commitment to Sport and Exercise: Re-examining the Literature for a Practical and Parsimonious Model
}

\section{Lavon Williams}

Sports Studies Department, Guilford College, Greensboro, NC, USA

A commitment to physical activity is necessary for personal health, and is a primary goal of physical activity practitioners. Effective practitioners rely on theory and research as a guide to best practices. Thus, sound theory, which is both practical and parsimonious, is a key to effective practice. The purpose of this paper is to review the literature in search of such a theory - one that applies to and explains commitment to physical activity in the form of sport and exercise for youths and adults. The Sport Commitment Model has been commonly used to study commitment to sport and has more recently been applied to the exercise context. In this paper, research using the Sport Commitment Model is reviewed relative to its utility in both the sport and exercise contexts. Through this process, the relevance of the Investment Model for study of physical activity commitment emerged, and a more parsimonious framework for studying of commitment to physical activity is suggested. Lastly, links between the models of commitment and individuals' participation motives in physical activity are suggested and practical implications forwarded.

Key words: Motivation, Personal satisfaction, Behavior, Motor activity, Physical fitness, Health

\section{INTRODUCTION}

Physical inactivity is a leading cause of most non-infectious diseases [1-3], including heart disease, some cancers, and type 2 diabetes. Non-infectious diseases account for approximately $60 \%$ of the 56 million deaths around the world annually and $47 \%$ of the global burden of disease, and this burden continues to grow [1]. These statistics demonstrate the importance of physical activity for healthy living and illustrate that physi-

Received: February 8, 2012 Accepted: September 6, 2012

Corresponding author: Lavon Williams, PhD

5600 West Friendly Avenue, Guilford College, Greensboro, NC 27410, USA

Tel: +1-336-315-2953, Fax: +1-336-316-2495

E-mail: Iwilliam@guilford.edu

This is an Open Access article distributed under the terms of the Creative Commons Attribution Non-Commercial License (http://creativecommons.org/licenses/bync/3.0// which permits unrestricted non-commercial use, distribution, and reproduction in any medium, provided the original work is properly cited. cal inactivity and the associated health-related problems have no geographical boundaries [3]. In light of this, commitment to sustained physical activity across the lifespan is imperative for personal health, and is a primary goal of physical activity specialists around the world.

When striving to promote the commitment to sustained physical activity, physical activity specialists are most effective when utilizing the best available research to guide their practice. At the heart of sound research is theory, making sound theory a key to effective practice [4]. To be sound, a theory must be both practical and parsimonious. This leads to the question, "what is the best theory to aid physical activity specialists in promoting a commitment to life-long physical activity?"

The purpose of this paper is to review the literature in search of a practical and parsimonious theory that applies to and explains commitment to both sport and exercise for children, adolescents, and adults. The Sport Commitment Model is an evolving theory that explains participation in physical activity in the sport context. This model has also recently been adapt- 
ed to exercise.

Physical activity is commonly defined as any bodily movement produced by skeletal muscles that results in energy expenditure [5], including sport and exercise. Sport is a form of physical activity that is highly organized and socially competitive [6], while exercise is physical activity that is planned, structured, repetitive, and designed to improve or maintain physical fitness [5]. For the specific purposes of this paper, the term physical activity refers to sport and exercise collectively because, as argued in the paper, sport and exercise motivation from a commitment perspective are more similar than different and one unified model is sufficient and parsimonious. However, to maintain the integrity of the original research discussed in this paper, original terms used by authors (e.g., sport or exercise) are used in this paper.

\section{PARTICIPATION MOTIVATION}

Commitment to physical activity impacts one's motivation for involvement. Motivation for participation is manifested in individuals' behavior in the form of their activity choices, how much effort they put forth in physical activity-related endeavors, and how long they persist, particularly in the face of obstacles and failure [7]. Of particular interest to physical activity and health professionals is creating environments in which individuals not only participate in physical activity, they will persist in being physically active.

Research shows that regardless of age, youth and adults participate in physical activity for similar reasons. When asked why they participate, youth sport participants responses generally fall among the following categories: fun, competence, affiliation, and fitness [7]. Adults respond with the same general motives when asked about their motivation for exercising [8]. That is, people, young and old, participate in sport and exercise, because it is fun, they like to strive to achieve and experience feelings of competence, they want to be with their friends and meet new people, and they see physical activity as an avenue for increasing fitness.

Despite the many perceived benefits of participation, people also withdraw from physical activity. In the United States, approximately one-third of all participants in organized youth sports drop out yearly [9] with the estimated average youth sport attrition rates ranging from $22 \%$ to $59 \%$ [10]. Attrition from physical activity programs among adults is also a concern. There has been a decrease in participation among popu- lar sport and fitness activities including, tennis, racquetball, aerobic dance, jogging/running, and weight lifting [11], and it is commonly reported that $50 \%$ of adults who begin an exercise program drop out within 3 to 6 months [12].

\section{THE SPORT COMMITMENT MODEL}

To better understand sport participants' motivation, Scanlan et al. [13], Scanlan et al. [14], Carpenter et al. [15], Carpenter et al. [16], and Carpenter et al. [17] began investigating the concept of sport commitment in the 1990s. These researchers defined sport commitment as a motivational force that reflects a person's desire and resolve to continue participation in sport. Sport commitment is a dynamic, psychological state that can vary over time, through seasons, and over the course of careers. Individuals' level of commitment influences behavior in the form of choice, persistence, and effort.

Through a combination of qualitative and quantitative studies, Scanlan et al. [13], Scanlan et al. [14], and Carpenter et al. [15] identified six determinants of sport commitment including sport enjoyment, involvement opportunities/benefits, personal investments, social support, involvement or attractive alternatives, and social constraints. Sport enjoyment is a positive emotional response to the sport experience. It is synonymous with concepts including fun, pleasure, and satisfaction. Involvement opportunities are the valued opportunities that are only available experientially through continued participation. These are the benefits that come with participating in sport. Personal investments are the personal resources such as time, energy, money, and effort that are put into the activity that cannot be recovered if participation is discontinued. Social support is the participant's perceived support and encouragement from significant others in response to the participant's involvement in sport. Involvement alternatives refer to the attractiveness or allure of other activities relative to one's current sport choice. Social constraints reflect expectations that create feelings of obligation to others such as parents, peers, and coaches to continue involvement in sport.

Of the six determinants, enjoyment, involvement opportunities, personal investments and social support have been found to be positively related to sport commitment among youth, elite-amateur, and professional sport athletes [13-17]. Of these, enjoyment and personal investments have been the most consistent predictors of sport commitment.

Though they have been found to predict commitment, in- 
volvement alternatives and social constraints have not consistently predicted commitment across all groups. For example, involvement alternatives has been shown to significantly predict sport commitment in adult and high school athletes. However, younger athletes do not appear to have the same understanding of this construct, possibly because younger athletes may not have to make competing choices regarding sport [5]. It is interesting to note that although social constraints is theorized to be positively related to sport commitment, research has demonstrated small negative or no relationship between social constraints and sport commitment in adult or youth sport [13-18]. These individuals may be participating because of their personal desire rather than feelings of obligation [15]. That is, participants play because they want to, not because they have to.

\section{ATTRACTION, ENTRAPMENT, AND LOW COMMITMENT}

The concept of individuals playing because they want to reflects an attraction-based commitment [19], which some researchers refer to as "want to" commitment $[20,21]$. Conversely, the notion that individuals play because they have to play, they have no choice, reflects an entrapment-based form of commitment or "have to" commitment [20,21]. Also, individuals are theorized to play with low commitment levels. Though not addressed by early sport commitment researchers, these three types of commitment were part of the early conceptual- ization of the Sport Commitment Model by Schmidt and Stein [19] and can be thought of as profiles denoting attractionbased (want to), entrapment-based (have to), and low commitment athletes.

Theoretically, the profiles of attraction-based, entrapment based, and low commitment are distinct (Figure 1A). Specifically, an attraction-based profile is theorized to reflect high enjoyment, involvement opportunities (in the form of high benefits and low costs), high personal investment, and low involvement alternatives. Athletes with an attraction profile are the most likely to continue their sport experience with positive feelings and attitudes.

The entrapment-based and low commitment profiles are theorized as distinct, but similar. Both profiles are expected to be associated with low enjoyment, low involvement opportunities (in the form of high costs and low benefits), and high personal investment. The difference between these profiles lies with involvement alternatives. Athletes with low commitment are theorized to see other activities as attractive, whereas entrapped athletes see none. In essence, athletes fitting the entrapment-based profile are motivated to continue playing because they have nothing better to do and/or they have put too much into the sport to quit. Athletes with an entrapped profile are the most likely to burnout. In contrast, athletes fitting the low commitment profile do see involvement alternatives, but have put much into the sport. While they may be tempted to quit, they tend to continue participating.

The three theoretical commitment profiles described above

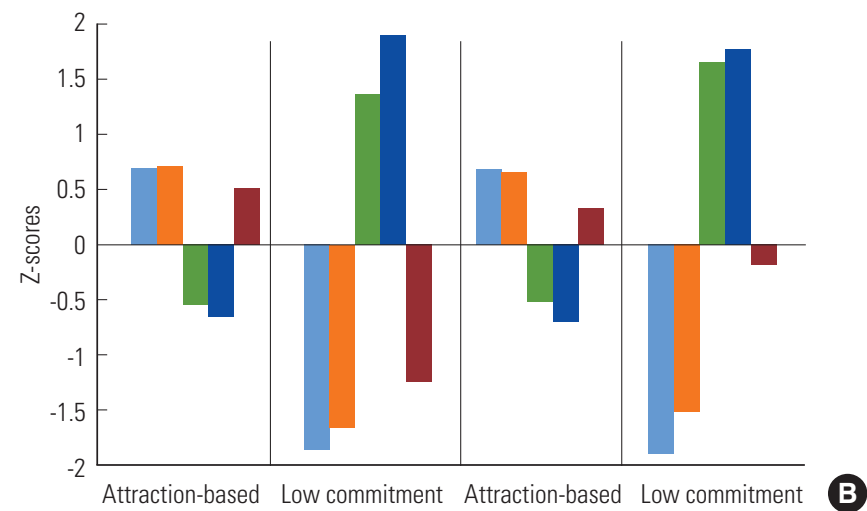

Figure 1. Sport commitment profiles. (A) Commitment profiles as theorized by Schmidt and Stein [19]. (B) Commitment profiles reported by Raedeke [22] (the two profiles on left) and Weiss and Weiss [23] (the two profiles on right). Z-scores above 0.5 denote high scores on its corresponding determinant. The determinants of commitment as noted in these profiles precedes the finalization of sport commitment determinants as depicted in this paper. Benefits is conceptual similar to involvement opportunities. The names associated with these profiles differ from those reported by Raedeke [22] and Weiss and Weiss [23]. This was done to illustrate that the profiles found in these studies do resemble the profiles theorized by Schmidt and Stein [19]. 
have been investigated empirically using cluster analysis. Specifically, Raedeke [22] and Weiss and Weiss [23], examined the relationship between commitment profiles and motivation-related behavior. Among the findings of these studies, only two profiles were found to be conceptually similar to the theoretical profiles (Figure 1B). Specifically, Raedeke [22] found profiles resembling attraction-based and low commitment among 13 to 18 years old competitive age-group swimmers and Weiss and Weiss [23] found similar profiles among 10 to 18 years old competitive club gymnasts. Interestingly, in neither study did an entrapment-based commitment profile emerge. In both studies, and as expected, the profile resembling the attractionbased profile was more positively associated with motivation. Specifically, swimmers in the attraction-based profile reported the lowest burnout, whereas those in the low commitment profile reported the greatest level of burnout. Similar results were found among the gymnasts. Those in the attractionbased profile reported greater intrinsic motivation, effort, and persistent, as well as lower amotivation than those in the low commitment profile. Based on these results and theory, coaches who create environments in which their athletes enjoy, value, and invest are likely to have committed athletes.

\section{SPORT COMMITMENT MODEL AND EXERCISE}

The perceived utility of the sport commitment model has led some to investigate its veracity in exercise- and leisure-related behavior [20,21]. Using the Sport Commitment Model as a guiding framework, Wilson and colleagues investigated commitment to exercise. Acknowledging that many exercise out of feelings of obligation as well as choice, Wilson et al. [20] conceptualized exercise commitment to reflect both functional (want to) and obligatory (have to) resolve to continue exercising. Relative to the Sport Commitment Model, they reconceptualized sport enjoyment as the degree to which exercisers perceive exercise as rewarding and labeled this as satisfaction. All remaining determinants are conceptually similar to the Sport Commitment Model, with the context being shifted from sport to exercise.

In their examination of the relationship between exercise commitment and exercise-related behavior, Wilson et al. [20] hypothesized: 1) two types of commitment including a volitional, attraction-based (i.e., want to) form of commitment and an obligatory, entrapment-based (i.e., have to) form of commitment; 2) exercise commitment would be positively re- lated to satisfaction, personal investment, involvement opportunities and social support, and differentially to involvement alternatives and social constraints; and 3) exercise commitment would be positively related to more frequent and intense exercise behavior. Interestingly, no specific hypotheses were made regarding the relationship between the determinants of exercise commitment and "want to" vs. "have to" commitment.

Partial support was found for their hypotheses based on the responses from 428 university students and staffers enrolled in group exercise classes who completed questionnaires assessing exercise commitment, determinants to exercise commitment, and the frequency in which they engaged in varying levels of exercise. Relative to the first hypothesis and using structural equation modeling, they found that exercise commitment was multidimensional with "want to" and "have to" commitment.

Relative to the second hypothesis involving the relationship between the determinants and commitment, only satisfaction and personal investment positively predicted both "want to" and "have to" commitment, with involvement opportunities and social constraints positively predicting "have to" commitment. Interestingly though, and relative to the third hypothesis, only "want to" commitment was related to self-report exercise behavior. These findings reveal that only satisfaction and personal investment relate to exercise behavior through exercise commitment. Practically speaking, individuals who experience greater satisfaction exercising and who perceive that they have put a greater investment of resources into exercising (e.g., time, money, energy, and effort) are 1) committed to exercise volitionally (i.e., because they want to) and 2) more apt to exercise than those who are less satisfied and perceive putting a lower investment of resources into exercise. As with the research on sport commitment, "want to" (aka, attractionbased) commitment served as a strong predictor of persistent exercise participation while the concept of "have to" (aka, obligatory or entrapped) commitment did not emerge as a predictor of exercise behavior.

\section{SPORT COMMITMENT MODEL: IS THERE A MORE PARSIMONIOUS EXPLANATION?}

This review of the sport commitment research has revealed that enjoyment/satisfaction and personal investment are the strongest most consistent determinants of commitment to physical activity. Based on this, physical activity specialists are 
advised to create environments in which people find enjoyment and are willing to invest. While practical and parsimonious, more research is needed to determine the adequacy of this conclusion. Can commitment to physical activity be reduced to two determinants and still explain motivation adequately?

When attempting to determine the best and most parsimonious model for fostering a commitment to physical activity through sport and exercise, the Investment Model [24,25] should be considered. The Investment Model, the model from which the Sport Commitment Model emerged [1], was proposed by Rusbult [24] to "predict (the) degree of commitment to and satisfaction with a variety of forms of ongoing associations (e.g., romantic relationships, friendship, and business) with wide ranges of duration and involvement" (p. 173). The similarities between the Investment Model and the Sport/Exercise Commitment Model are evident in the determinants and nature of commitment proposed in both models.

Rusbult [24] identified five determinants of commitment including satisfaction/attraction to an association, attractive alternatives, investments, the rewards or benefits of an association, and the costs of an association. Rusbult's five determinants of commitment are conceptually consistent with sport enjoyment/exercise satisfaction, involvement alternatives, personal investments, and involvement opportunities, respectively. It is noteworthy that while cost was initially considered by Schmidt and Stein [19], it is not a specific determinant of the Sport Commitment Model.

Second, Rusbult [24] acknowledged the multidimensional nature of commitment when she stated that "high investments and/or poor alternatives may sometimes serve to trap the individual in an unhappy, unsatisfying relationship rendering it possible to have high commitment while satisfaction and attraction to the ongoing association are low" (p. 175). In light of 1) the similarities between the commitment models developed in physical activity contexts (sport and exercise) and the Investment Model, 2) the original intention for the Investment Model to predict commitment in a variety of contexts, 3) the role of satisfaction and personal investment in explaining physical activity commitment, 4) the meaningfulness of the concept of costs in the study of physical activity commitment, and 5) the value of conceptual parsimony, the Investment Model deserves further consideration as a more efficient and equally as effective model for predicting physical activity behavior than the Sport Commitment Model.

\section{THE INVESTMENT MODEL APPLIED TO EXERCISE}

Recently, the Investment Model was, in part, applied to the exercise setting. Gabriele et al. [21] examined the relationships among exercise commitment, determinants of exercise commitment, and exercise-related behavior. They considered only three determinants including satisfaction, personal investment, and involvement alternatives. These determinants are all conceptually consistent with the determinants included in the Investment Model. They assessed both "want to" and "have to" commitment, and exercise behavior was assessed in terms of the participants' stage of behavior change and time spent in leisure physical activity across seven days.

Although they did not forward specific hypotheses, it is reasonable to suggest that they expected that 1) satisfaction and personal investments would relate positively to both forms of commitment, 2) involvement alternatives would relate positively to "want to" and negatively to "have to" commitment, and 3) "want to" and "have to" forms of commitment would both relate positively to stages of behavior change and time spent exercising. The responses from 267 individuals participating in university classes, private health clubs, and a community running club were analyzed using structural equation modeling and multivariate analyses. Results revealed that satisfaction and personal investments related positively to "want to" and "have to" commitment, but attractive alternatives only related to "have to" commitment. Additionally, only "want to" commitment related to exercise-related behavior. These finding are congruent with Wilson et al. [20]. Collectively, results of these studies support the conclusion that satisfaction and personal investments are two keys to fostering "want to" commitment, and exercise behavior.

\section{CONCLUSIONS AND PRACTICAL IMPLICA- TIONS}

Undoubtedly, more research is needed to draw meaningful conclusions. A review of the literature across sport and exercise in conjunction with the Sport Commitment and Investment Models reveals that satisfaction/enjoyment and personal investments are consistent predictors of commitment to persistent participation in physical activity in the form of sport and exercise. Additionally, attraction-based or "want to" commitment is a consistent predictor of both sport and exercise be- 
havior. In fact, given the results of the research on sport and exercise commitment, it is can be argued that the Investment Model may be as practical as and provide a more parsimonious explanation of commitment to sport and exercise than the Sport Commitment Model.

More research is needed to clarify the utility and parsimony of the Investment Model and Sport Commitment Model when promoting long-term participation in sport and exercise across the lifespan, and to extend this literature to include other physical activity settings such as rehabilitation. Research employing structural equation modeling and experimental design would contribute greatly to our understanding of commitment to physical activity and finding the most parsimonious explanation to what leads to persistent involvement in physical activity.

From a practical standpoint, the research on exercise and sport commitment emphasizes the importance of fostering "want to" physical activity behavior, and affirms that creating fun environments and valued experiences are important factors. Enjoyment is a significant factor in our practical understanding of commitment for several reasons. First, enjoyment/ satisfaction have been consistent predictors of physical activity participation [13-15]. Second, some have argued that enjoyment mediates the relationship between commitment and its determinants [26]. Lastly, fun is a primary reason people give for participating in physical activity. No doubt, creating situations and environments that are enjoyable is paramount to fostering physical activity.

Scanlan et al. [27] and Scanlan et al. [28] examined sources of sport enjoyment. Among youth they found that social interactions with coaches, parents, and teammates; demonstrating one's ability; mastering skills; and being effortful were all sources of fun [27]. When reflecting back on their sport experiences, former elite figure skaters revealed that they found enjoyment in 1) the act of skating, 2) competitive achievements including skill mastery and demonstrating athletic ability, and 3) social opportunities, such as recognition for their accomplishments and ability, friendship opportunities, and relationships with their coaches [28]. When viewed together, sources of enjoyment mentioned by youth and adults are similar. Sport is enjoyable and fun, because sport provides opportunities for social affiliation, achievement/mastery, and movement (fitness).

These findings regarding sources of enjoyment are noteworthy, particularly in relation to individuals' motives for participation in physical activity. Consider the similarities between the primary reasons youth and adults give for participating in physical activity and their sources of enjoyment. Both participate in physical activity for fun and social affiliation, to build competence/strive for success, and for fitness. They enjoy the sport experience through social affiliation, achievement, and movement/play. Put within the discussion of sport commitment, if the physical activity experience can be designed to meet people's motives for participation in the form of social, achievement, and movement opportunities, they will be more likely to enjoy themselves, commit to sport volitionally, and thus be more physically active.

In conclusion, the increasing health cost of physical inactivity around the world should impress upon all of us the importance of one's commitment to physical activity whether through sport or exercise. While the Sport/Exercise Commitment Model has provided insight into the understanding of sport commitment, the results highlight the potential relevance and more parsimonious approach of the Investment Model. The Investment Model when applied to sport and exercise context may provide an explanation of commitment to physical activity that is as adequate as, and more parsimonious than, the Sport/ Exercise Commitment Model. No doubt, continued research on commitment to physical activity using and testing both the Sport/Exercise Commitment Model and the Investment Model is necessary to provide a clear understanding of this construct and its relationship with physical activity behavior.

Collectively, research on sport and exercise commitment to date sends a clear message to physical activity leaders, practitioners, and others desiring to affect physical activity levels and persistence. To foster attraction-based, "want to" commitment to physical activity in the form of sport and exercise, we need to facilitate enjoyment of physical activity and personal investments in physical activity. Those who enjoy and invest in physical activity are most likely to be committed to participation because they "want to" be involved. It is reasonable to suggest that physical activity professionals can foster a greater attraction-based, "want to" commitment among the youth and adults by focusing on creating fun physical activity environments in which people experience competence, social affiliation, and increased fitness. These environments are more likely to foster greater enjoyment and feelings of personal investment and promote "want to" participation in physical activity. 


\section{ACKNOWLEDGEMENTS}

Appreciation is extended to three anonymous reviewers and Dr. Diane Guinan for comments to an earlier version of this manuscript.

\section{CONFLICT OF INTEREST}

The author has no conflicts of interest with the material presented in this paper.

\section{REFERENCES}

1. World Health Organization. Global strategy on diet, physical activity, and health. Geneva: World Health Organization; 2004, p. 2.

2. US Department of Health and Human Services. Physical activity and health: a report of the Surgeon General. Atlanta: US Department of Health and Human Services; 1996, p. 5-7.

3. Chen LJ, Haase AM, Fox KR. Physical activity among adolescents in Taiwan. Asia Pac J Clin Nutr 2007;16(2):354-361.

4. Gill DL, Williams L. Psychological dynamics of sport and exercise. 3rd ed. Champaign: Human Kinetics; 2008, p. 24.

5. Caspersen CJ, Powell KE, Christenson GM. Physical activity, exercise, and physical fitness: definitions and distinctions for health-related research. Public Health Rep 1985;100(2):126131.

6. Coakley JJ. Sports in society: issues and controversies. 10th ed. Boston: McGraw Hill; 2009, p. 6.

7. Weiss MR, Ferrer-Caja E. Motivational orientations and sport behavior. In: Horn TS, editors. Advances in sport psychology. 2nd ed. Champaign: Human Kinetics; 2002, p. 101-183.

8. Campbell PG, MacAuley D, McCrum E, Evans A. Age differences in the motivating factors for exercise. J Sport Exerc Psychol 2001;23(3):191-199.

9. Burton D, O'Connell K, Gillham AD, Hammermeister J. More cheers and fewer tears: examining the impact of competitive engineering on scoring and attrition in youth flag football. Int J Sports Sci Coach 2011;6(2):219-228.

10. Gould D. Understanding attrition in children's sport. In: Gould D, Weiss M, editors. Advances in pediatric sport sciences: behavioral issues. Vol. 2. Champaign: Human Kinetics; 1987, p. 61-85.

11. Howard DR. Participation rates in selected sport and fitness activities. J Sport Manag 1992;6(3):191-205.
12. Dishman RK, Buckworth J. Increasing physical activity: a quantitative synthesis. Med Sci Sports Exerc 1996;28:706-719.

13. Scanlan TK, Carpenter PJ, Schmidt GW, Simons JP, Keeler B. An introduction to the Sport Commitment Model. J Sport Exerc Psychol 1993;15(1):1-15.

14. Scanlan TK, Simons JP, Carpenter PJ, Schmidt GW, Keeler B. The Sport Commitment Model: measurement development for the youth-sport domain. J Sport Exerc Psychol 1993;15(1): 16-38.

15. Carpenter PJ, Scanlan TK, Simons JP, Lobel M. A test of the Sport Commitment Model using structural equation modeling. J Sport Exerc Psychol 1993;15(2):119-133.

16. Carpenter PJ, Coleman R. A longitudinal study of elite youth cricketers' commitment. Int J Sport Psychol 1998;29(3):195-210.

17. Carpenter PJ, Scanlan TK. Changes over time in the determinants of sport commitment. Pediatr Exerc Sci 1998;10(4):356365.

18. Scanlan TK, Russell DG, Beals KP, Scanlan LA. Project on Elite Athlete Commitment (PEAK). II. A direct test and expansion of the Sport Commitment Model with elite amateur sportsmen. J Sport Exerc Psychol 2003;25(3):377-401.

19. Schmidt GW, Stein GL. Sport commitment: a model integrating enjoyment, dropout, and burnout. J Sport Exerc Psychol 1991;13(3):254-265.

20. Wilson PM, Rodgers WM, Carpenter PJ, Hall C, Hardy J, Fraser $\mathrm{SN}$. The relationship between commitment and exercise behavior. Psychol Sport Exerc 2004;5(4):405-421.

21. Gabriele JM, Gill DL, Adams CE. The roles of want to commitment and have to commitment in explaining physical activity behavior. J Phys Act Health 2011;8(3):420-428.

22. Raedeke TD. Is athlete burnout more than just stress? A sport commitment perspective. J Sport Exerc Psychol 1997;19(4): 396-417.

23. Weiss WM, Weiss MR. A longitudinal analysis of commitment among competitive female gymnasts. Psychol Sport Exerc 2006;7(3):309-323

24. Rusbult CE. Commitment and satisfaction in romantic associations: a test of the investment model. J Exp Soc Psychol 1980; 16(2):172-186.

25. Rusbult CE, Farrell D. A longitudinal test of the investment model: the impact on job satisfaction, job commitment, and turnover of variations in rewards, costs, alternatives, and investments. J Appl Psychol 1983;68(3):429-438.

26. Weiss MR, Kimmel LA, Smith AL. Determinants of sport commitment among junior tennis players: enjoyment as a medi- 
ating variable. Pediatr Exerc Sci 2001;13(2):131-144.

27. Scanlan TK, Carpenter PJ, Lobel M, Simons JP. Sources of enjoyment for youth sport athletes. Pediatr Exerc Sci 1993;5(2): 275-285.
28. Scanlan TK, Stein GL, Ravizza K. In-depth study of former elite figure skaters. II. Sources of enjoyment. J Sport Exerc Psychol 1989;11(1):65-83. 